\title{
Элементоорганические регуляторы роста нового поколения на чесноке
}

\author{
Organic element growth regulators of the new generation while garlic growing
}

\section{Поляков А.В., Логинов С.В., Алексеева Т.В., Стороженко П.А.}

\section{Аннотация}

Целью исследования было определение эффективности применения элементоорганических регуляторов роста нового поколения при возделывании чеснока (Allium sativum L.). Исследования проведены во ВНИИО - филиале ФГБНУ ФНЦО, в условиях открытого грунта в период 2018-2019 годов. Почва опытного участка супесчаная, содержание гумуса в ней составляет 3,41-3,44\%. Реакция среды нейтральная - $\mathrm{pH}_{\mathrm{KCl}} 6,7$. Степень обеспеченности питательными веществами: фосфором - высокая (содержание $\mathrm{P}_{2} \mathrm{O}_{5}$ в слое 0-20 см составляет 22,78-24,62 мг на 100 г почвы (по Чирикову); калием - низкая, содержание $\mathrm{K}_{2} \mathrm{O}$ в слое 20 см - 10,38-17,88 мг на 100 г почвы (по Масловой). Для улучшения минерального питания растений в почву вносили калий хлористый в дозе 50 г/M². В период вегетации растений использовали подкормки: первую, в фазе начала интенсивного роста листьев аммиачной селитрой в дозе 30

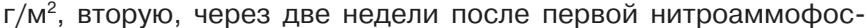

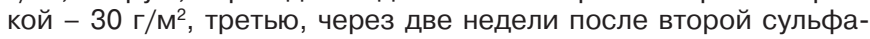
том калия - 50 г/ $\mathrm{M}^{2}$. Погодные условия в целом были благоприятными для выращивания чеснока. Полив растений проводили по мере подсыхания верхнего слоя почвы. Материалом для исследования являлся чеснок озимый сорта Гладиатор. Схема опыта предполагала трехкратную обработку растений, полученных из воздушных луковичек, препаратами: Лостор в концентрации $0,1 \%+0,1 \%+0,1 \%$, Энергия М 0,01\%+0,01\%+0,01\%, Силиплант $0,3 \%+0,2 \%+0,3 \%$, Циркон - 0,025\%+0,01\%+0,01\%. Обработку растений, проводили путем опрыскивания в период вегетации. Обработку растений, полученных из зубков, препаратами: Боратран в сочетании с Крезацином и Асяком в концентрации 0,015\%; Герматранол в сочетании с Крезацином и Асяком в концентрации 0,015\%, Лостор в концентрации 0,01\%, растворенных в 1\% растворе ДМСО. Установлено, что при обработке растений препаратом Лостор урожайность однозубковых луковиц повысилась на 24,6\% по сравнению с контролем, а при использовании препарата Энергия М - на 15,9\%, что обусловлено лучшей выживаемостью растений. При обработке растений растворами: Боратрана в сочетании с Крезацином и Асяком, Герматранола в сочетании с Крезацином и Асяком, Лостора, масса луковиц, в зависимости от варианта, превышала контроль на 11,5-12,6\%, а урожайность на 12,1-17,7\%. Доля пораженных луковиц составила от $0,8 \%$ до $1,3 \%$.

Ключевые слова: элементоорганические регуляторы роста, чеснок озимый, зубок, растение.

Для цитирования: Элементоорганические регуляторы роста нового поколения на чесноке / А.В. Поляков, С.В. Логинов, Т.В. Алексеева, П.А. Стороженко // Картофель и овощи. 2020. № 4. С. 26-28. https://doi.org/10.25630/PAV.2020.31.15.001

\section{Polyakov A.V., Loginov S.V., Alekseeva T.V., Storozhenko P.A.}

\section{Abstract}

The purpose of the investigation was to determine the effectiveness of the use of organic element growth regulators of the new generation under cultivation of garlic (Allium sativum L.). The investigation was carried out in ARRIVG-branch of the Federal state budgetary Institute, in open ground conditions in the period 2017-2019. The soil of the experimental plot was sandy loam, the humus content in it was $3.41-3.44 \%$. The reaction of soil solution was neutral- $\mathrm{pH}_{\mathrm{KC}} 6,7$. The degree of nutrient availability: phosphorus was high $\left(\mathrm{P}_{2} \mathrm{O}_{5}\right.$ content in the $0-20 \mathrm{~cm}$ layer was $22.78-24.62 \mathrm{mg}$ per 100 $\mathrm{g}$ of soil (according to Chirikov); potassium - low, the content of $\mathrm{K}_{2} \mathrm{O}$ in a layer of $20 \mathrm{~cm}-10.38-17.88 \mathrm{mg}$ per $100 \mathrm{~g}$ of soil (according to Maslowa). To improve mineral nutrition of plants in the soil potassium chloride was added at a dose of $50 \mathrm{~g} / \mathrm{m}^{2}$. During the vegetation period of plants supplements were used: first, in the early phase of intensive growth of leaves by ammonium nitrate $-30 \mathrm{~g} / \mathrm{m}^{2}$, the second, 2 weeks after the first by complex fertilizer Nitroammophoska and the third - by potassium sulphate $-50 \mathrm{~g} / \mathrm{m}^{2}$. Weather conditions were generally favorable for growing garlic. Watering of plants was carried out as the top layer of soil dried. As plant material for the investigation it was used winter garlic of Gladiator cultivar. The scheme of the experiment assumed three-time treatment of plants with preparation: Lostor in a concentration of $0.1 \%+0.1 \%+0.1 \%$, Energy M $0.01 \%+0.01 \%+0.01 \%$, Siliplant - 0,3\%+0,2\%+0,3\%, Zircon $-0,025 \%+0,01 \%+0,01 \%$. Treatment of plants was carried out by spraying during the growing season. Treatment of plants was carried out by Boratran in combination with Krezatsin and Asiac at a concentration of $0.015 \%$, Germatranol in combination with Krezatsin and Asiac at a concentration of $0.015 \%$, Lostor at a concentration of $0.01 \%$ dissolved in $1 \%$ solution of DMSO. It was found that treatment of plants with Lostor increased the yield of single-tooth bulbs by $24.6 \%$ compared to the control and using Energia M-by $15.9 \%$ because of better plant survival. Treatment of plants with Boratran in combination with Cresacin and Asyak, Germatranol in combination with Cresacin and Asyak, Lostor increased the weight of bulbs by $11.5-12.6 \%$ and the yield by $12.1-17.7 \%$. The percentage of affected bulbs ranged from $0.8 \%$ to $1.3 \%$ plant.

Key words: organic element growth regulators, winter garlic, teeth,

For citing: Organic element growth regulators of the new generation while garlic growing. Polyakov A.V., Loginov S.V., Alekseeva T.V., Storozhenko P.A. Potato and vegetables. 2020. No4. Pp. 26-28. https://doi.org/10.25630/PAV.2020.31.15.001 (In Russ.)
П олучение высокого качественного урожая на сегодняшний день практически невозможно без использования современных регуляторов роста. На потребительском рынке можно встретить большой ассортимент регуляторов рос- та, которые предназначены для выращивания разных видов овощных культур. Многие из них, как пишут производители, пригодны для использования практически для всех видов культур. Однако не всегда они способны в полной мере раскрыть биологический потенциал растений, и позволяют получить высокие урожаи. В связи с этим достаточно остро стоит вопрос разработки и использования новых регуляторов роста, которые стимулируют физиологические процессы, повышают устойчи- 
Таблица 1. Эффективность применения регуляторов роста при производстве однозубковых луковиц (2018-2019 годы)

\begin{tabular}{|c|c|c|c|c|c|c|c|}
\hline \multirow{2}{*}{ Вариант опыта } & \multicolumn{2}{|c|}{$\begin{array}{c}\text { Число растений перед } \\
\text { уборкой }\end{array}$} & \multicolumn{2}{|c|}{ Масса луковицы } & \multicolumn{2}{|c|}{ Урожайность луковиц } & \multirow{2}{*}{$\begin{array}{c}\text { Доля } \\
\text { пораженных } \\
\text { луковиц } \\
\%\end{array}$} \\
\hline & шт/M $\mathrm{M}^{2}$ & $\%$ & г & $\%$ & т/га & $\%$ & \\
\hline Контроль (обработка водой) & 340 & 100,0 & 1,6 & 100,0 & 5,15 & 100,0 & 1,2 \\
\hline Лостор & 431 & 126,8 & 1,5 & 93,7 & 6,42 & 124,6 & 0 \\
\hline Энергия M & 375 & 110,3 & 1,6 & 100,0 & 5,97 & 115,9 & 1,2 \\
\hline Силиплант & 367 & 107,9 & 1,5 & 93,7 & 5,43 & 105,4 & 0,2 \\
\hline Циркон & 353 & 103,8 & 1,4 & 87,5 & 4,94 & 95,9 & 0,9 \\
\hline $\mathrm{HCP}_{05}$ & & & & & 0,35 & & \\
\hline
\end{tabular}

вость растений к неблагоприятным природным условиям и способствуют усилению неспецифического иммунитета растений.

Элементоорганические регуляторы роста сейчас активно синтезируют и исследуют на различных культурах: свекле [1], томатах, белокочанной капусте, моркови столовой $[2,3]$.

Целью нашего исследования было определение эффективности применения элементоорганических регуляторов роста нового поколения при возделывании чеснока (Allium sativum L.)

Условия, материалы и методы исследований

Опыты проведены во ВНИИО - филиале ФГБНУ ФНЦО (д. Верея Раменского района, Московской области) в 20182019годахв открытом грунте.

Почва опытного участка супесчаная, содержание гумуса в слое 0-20 см составляет 3,41-3,44\%; в слое 20-40 см - 2,91-3,02\%. Реакция среды нейтральная - $\mathrm{pH}$ солевой вытяжки 6,7. Гидролитическая кислотность 0,72-0,92 мг-экв. на 100 г почвы, содержание суммы поглощенных оснований 46-50 мг-экв. на 100 г почвы. Степень обеспеченности питательными веществами: фосфором - высокая (содержание $\mathrm{P}_{2} \mathrm{O}_{5}$ в слое 0-20 см составляет 22,7824,62 мг на 100 г почвы (по Чирикову); калием - низкая, содержание К в слое 20 см - 10,38-17,88 мг на 100 г почвы (по Масловой). Удельный вес почв пахотного слоя 0-25 см состав-

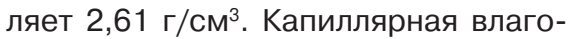
емкость: 43-44\%. Гигроскопическая влажность: 8,25\%.

Для улучшения минерального питания растений в почву вносили калий хлористый в дозе 50 г/ $\mathrm{M}^{2}$. В период вегетации растений использовали подкормки: первую, в фазе начала интенсивного роста листьев аммиачной селитрой в дозе 30 г/ $\mathrm{M}^{2}$, вторую, через две недели после первой

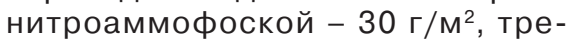
тью, через две недели после вто-

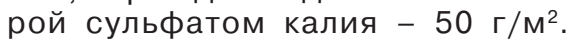
Погодные условия в целом были благоприятны для выращивания чеснока. Полив растений проводили по мере подсыхания верхнего слоя почвы.

Материалом для исследований служили воздушные луковички и зубки чеснока озимого (Allium sativum L.) сорта Гладиатор (рис.) [4], внесенного в Государственный реестр Российской Федерации.

В опытах использовали регуляторы роста и композиции, производимые ООО «Флора Си» - Энергия М, Лостор, Боратран+Крезацин+Асяк, ГНЦ РФ АO «ГНИИХТЭОС) Герматранол+Крезацин+Асяк, Герматранол, а также Силиплант и Циркон, производимые АНО «НЭСТ М».

Таблица 2. Урожайность и масса луковиц чеснока озимого сорта Гладиатор, полученных из зубков (2018-2019 годы)

\begin{tabular}{|c|c|c|c|c|c|}
\hline \multirow{2}{*}{ Вариант } & \multicolumn{2}{|c|}{ Масса луковицы } & \multicolumn{2}{|c|}{$\begin{array}{c}\text { Урожайность } \\
\text { луковиц }\end{array}$} & \multirow{2}{*}{$\begin{array}{c}\text { Доля пораженных } \\
\text { луковиц, \% }\end{array}$} \\
\hline & r & $\%$ & т/га & $\%$ & \\
\hline $\begin{array}{l}\text { Контроль (обработка } \\
\text { водой) }\end{array}$ & 34,9 & 100,0 & 12,4 & 100,0 & 1,0 \\
\hline $\begin{array}{l}\text { Боратран+ Крезацин+ } \\
\text { Асяк }\end{array}$ & 39,1 & 112,0 & 14,4 & 116,1 & 1,3 \\
\hline $\begin{array}{l}\text { Герматранол+ Креза- } \\
\text { цин+ Асяк }\end{array}$ & 38,9 & 111,5 & 13,9 & 112,1 & 0,9 \\
\hline Лостор & 39,3 & 112,6 & 14,6 & 117,7 & 0,8 \\
\hline $\mathrm{HCP}_{05}$ & \multicolumn{2}{|c|}{ - } & 0,6 & \multicolumn{2}{|r|}{ - } \\
\hline
\end{tabular}

При исследовании влияния регуляторов роста на массу и урожайность луковиц использовали трехкратную обработку растений, полученных из воздушных луковичек, препаратами: Лостор в концентрации $0,1 \%+0,1 \%+0,1 \%$, Энергия М $0,01 \%+0,01 \%+0,01 \%$, Силиплант $0,3 \%+0,2 \%+0,3 \%$, Циркон 0,025\%+0,01\%+0,01\%. Обработку растений проводили путем опрыскивания в период вегетации. Опыт заложен в семикратной повторности, площадь учетной делянки составляла 1,0 м². Обработку растений, полученных из зубков, проводили препаратами Боратран в сочетании с Крезацином и Асяком в концентрации 0,015\%; Герматранол в сочетании с Крезацином и Асяком в концентрации 0,015\%; Лостор в концентрации 0,01\%, растворенных в 1\% растворе ДМСО. Повторность опыта шестикратная, площадь учетной делянки составляла 1,0 м². В качестве контроля использовали опрыскивание водой.

Растения были выращены в условиях открытого грунта на опытном участке, расположенном около ВНИИО - филиала ФГБНУ ФНЦО, по общепринятым методикам [5].

При обработке экспериментальных данных использованы общепринятые математико-статистические методы [6].

Результаты исследований. Проведенные нами исследования показали, что при обработке воздушных луковичек регуляторами роста (Лостор, Энергия М, Силиплант, Циркон) существенной прибавки массы однозубковых луковиц не наблюдалось. Однако использование препаратов Лостор и Энергия М значительно повлияло на повышение урожайности однозубковых луковиц. Так, при обработке растений препаратом Лостор урожайность однозубковых луковиц повысилась на 24,6\% по сравнению с контролем, а при ис- 


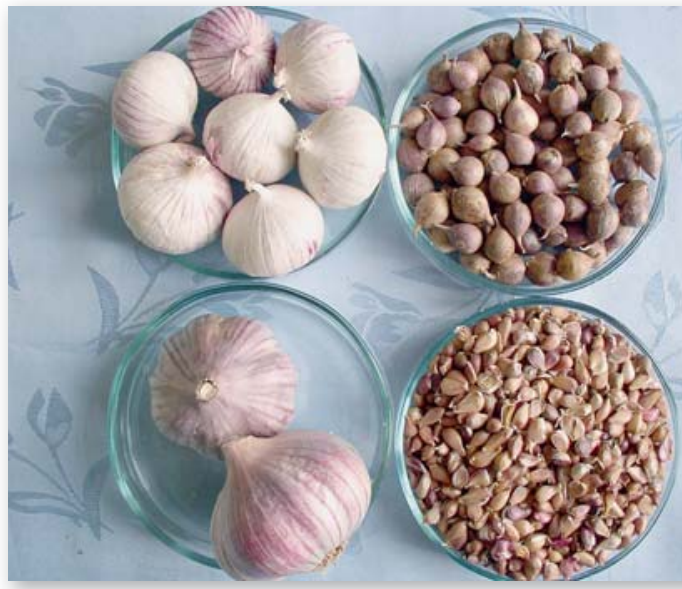

Воздушные луковички, однозубковые и многозубковые луковицы чеснока озимого сорта Гладиатор пользовании препарата Энергия М - на 15,9\%. В этих вариантах наблюдалась лучшая выживаемость растений, что и объясняет причину получения прибавки урожая (табл. 1). Доля пораженных однозубковых луковиц во всех вариантах была не выше 1,2\%.

Обработка растений, полученных из зубков, кремнийорганическими регуляторами роста, положительно сказалась на массе и урожайности луковиц. Так, масса луковиц, в зави-

\section{Библиографический список}

1.Синтез борсодержащих производных трис (2 -гидроксиэтил) аммония и их влияния на рост и развитие растений / И.А. Даин, С.В. Логинов, А.В. Лебедев, П.А. Стороженко // Вестник ВГУИТ. 2017. T. 79. №4. С. 165-174.

2.Петриченко В.Н., Логинов С.В., Туркина О.С. Влияние совместного использования регуляторов роста растений и фунгицидов на продуктивность томатов // Вестник РАЕН. 2014 . №6. C. $26-30$.

3.Петриченко В.Н., Логинов С.В., Туркина О.С. Влияние нанодисперсных биогенных металлов на эффективность регуляторов роста и продуктивность овощных культур // Аграрная Россия. 2015. №1. С. 10-13.

4.Поляков А.В. Гладиатор - новый сорт чеснока озимого // Картофель и овощи. 2013. № 9. С. 19-21.

5.Литвинов С.С. Методика полевого опыта в овощеводстве. М.: ГНУ ВНИИО, 2011. 650 с.

6.Доспехов Б.А. Методика полевого опыта (с основами статистической обработки результатов исследований). М: Агропромиздат, 1985. 351 с.

\section{Об авторах}

Поляков Алексей Васильевич, доктор биол. наук, профессор, г.н.с., заведующий отделом биотехнологии и инновационных проектов Всероссийского научно-исследовательского института овощеводства - филиала ФГБНУ ФНЦО (ВНИИО филиал ФГБНУ ФНЦО); и.о. заведующего кафедры ботаники и прикладной биологии Московского государственного областного университета (МГОУ). Тел. +7(906)707-69-47. E-mail: vita100plus@yandex.ru

Логинов Сергей Витальевич, доктор хим. наук, в.н.с., Государственный Научный Центр Российской Федерации, Акционерное Общество «Государственный научно-исследовательский институт химии и технологии элементоорганических соединений». Тел.: +7(965)180-07-63. E-mail: florasilik@yandex.ru

Алексеева Татьяна Вячеславовна, канд. с.-х. наук, м.н.с. отдела биотехнологии и инновационных проектов Всероссийского научно - исследовательского института овощеводства - филиала ФГБНУ ФНЦО (ВНИИО - филиал ФГБНУ ФНЦО); старший преподаватель кафедры ботаники и прикладной биологии Московского государственного областного университета (МГОУ). Тел. +7(915)460-26-05. E-mail: matilda8691@gmail.com

Стороженко Павел Аркадьевич, академик РАН, доктор хим. наук, Государственный Научный Центр Российской Федерации, временный ген. директор АO «Государственный научно-исследовательский институт химии и технологии элементоорганических соединений». Тел. +7(495)673-72-01 E-mail: info@eos.su симости от варианта, превышала контроль на 11,5-12,6\%, а урожайность - на 12,1-17,7\%. Доля пораженных луковиц составила от 0,8\% до 1,3\% (табл. 2).

\section{Выводы}

В результате исследований установлено, что обработка растений чеснока озимого элементоорганическим регуляторам роста Лостор способствуют лучшей выживаемости растений и повышению урожайности однозубковых луковиц на 24,6\%, а многозубковых луковиц - на 17,7\%. При этом доля пораженных луковиц фитопатогенными грибами и бактериями не превышала 0,8\%.

\section{References}

1.Synthesis of boron-containing derivatives of tris (2-hydroxyethyl) ammonium and their effects on the growth and development of plants. I.A. Dain, S.V. Loginov, A.V. Lebedev, P.A.Storozhenko. Vestnik VSUIT. 2017. Vol. 79. No4. Pp. 165-174 (In Russ.).

2.Petrichenko V.N., Loginov S.V., Turkina O.S. Influence of joint use of plant growth regulators and fungicides on tomato productivity. Vestnik RAEN. 2014. No6. Pp. 26-30 (In Russ.).

3.Petrichenko V.N., Loginov S.V., Turkina O.S. Influence of nanodisperse biogenic metals on the efficiency of growth regulators and productivity of vegetable crops. Agrarian Russia. 2015. No1. Pp. 10-13 (In Russ.).

4.Polyakov A.V. Gladiator - a new variety of winter garlic. Potato and vegetables. 2013. No9. Pp. 19-21 (In Russ.).

5.Litvinov S.S. Method of field experience in vegetable growing. Moscow. VNIIO. 2011. 650 p. (In Russ.).

6.Dospekhov B.A. Method of field experience (with the basics of statistical processing of research results). Moscow. Agropromizdat. 1985. 351 p. (In Russ.).

\section{Authors detail}

Polyakov A.V., Doctor Sci. (Biol.), professor, chief research fellow, head of biotechnological and international project department, All-Russian Research Institute of Vegetable Growing branch of Federal State Budgetary Research Enterprise Federal Research Centre of Vegetables (ARRIVG - branch of FSBSI FSCV); acting head of department botany and applied biology Moscow Region State University (MRSU). Phone: +7(906)707-69-47. E-mail: vita100plus@yandex.ru

Loginov S.V., Doctor Sci. (Chem.), leading research fellow, The State Scientific Center of the Russian Federation State Research Institute for Chemistry and Technology of Organoelement Compounds. Phone: +7(965)180-07-63. E-mail: florasilik@yandex.ru

Alekseeva T.V., Cand. Sci. (Agr.), junior research fellow, department of biotechnological and international project, All-Russian Research Institute of Vegetable Growing - branch of Federal State Budgetary Research Enterprise Federal Research Centre of Vegetables (ARRIVG - branch of FSBSI FSCVG); senior lecturer of department of botany and applied biology Moscow State Regional University (MRSU). Phone: +7(915)460-26-05. E-mail: matilda8691@ gmail.com

Storozhenko P.A., academician of RAS, Doctor Sci. (Chem.), The State Scientific Centre of the Russian Federation State Research Institute for Chemistry and Technology of Organoelement Compounds». Phone: +7(495)673-72-01. E-mail: info@eos.su 